\title{
FORMALDEHYDE-FREE AND HALOGEN-FREE FLAME RETARDANT FINISHING ON COTTON FABRIC
}

\author{
Zeynep OMEROGULLARI BASYIGIT ${ }^{1}$, Dilek KUT ${ }^{2}$ \\ ${ }^{1}$ Uşak University, Faculty of Engineering, Textile Engineering Department, Usak, Turkey. \\ ${ }^{2}$ Uludag University, Faculty of Engineering, Textile Engineering Department, Bursa, Turkey.
}

Received: 18.01.2018

Accepted: 16.05 .2018

\begin{abstract}
This study focuses on the application of environmental-friendly flame retardant (FR) finishing which does not include formaldehyde or halogen based chemicals on cotton fabrics since it has been announced that these kinds of materials have environmental and toxicological hazards. Three different types of FR agents were used in the finishing bath and applied on raw, pre-treated and dyed cotton fabrics, respectively. One of them was the mixture of inorganic and organic salts while the other type was chosen as phosphate structured which have a commercial use in textile industry widely in order to compare the flame retardant effects on cotton. The third type was calcium carbonate based chemical produced in Balıkesir Turkey named Firetex. After finishing treatment of all types of FRs, performance tests as burning tests and color spectrums were carried out beside the characterization tests as SEM and FTIR-ATR analysis. In order to determine the washing durability of the cotton fabrics, each performance test was performed after 5 repeated washing cycle. According to the results, it was observed that both three types of flame retardant agents improved the flame retardant effect of cotton fabrics however the char length of cotton fabric which treated with Firetex was lower than the rest and it was indicated in the study that using natural structured FR could be a new area in green chemistry as a FR textile chemical.
\end{abstract}

Keywords: Cotton fabric, non-formaldehyde, natural structured flame retardant, Firetex

Corresponding Author: Zeynep Omerogulları Basyigit e-mail: zeynep.omerogullari@usak.edu.tr / DOI: 10.32710/tekstilvekonfeksiyon.482884

\section{INTRODUCTION}

Despite the fact that cotton is the most commonly used naturaltextile fiber, it is one of the most flammable materials (LOI 18.4\%) which causes serious damage to the life and property $[4,10,12,18,21-22,24]$. The pyrolysis of cellulose is described in Fig. 1 as degradation initiated by a heterolytic bond scission. It is indicated that the volatile monomer levoglucosan which is the 1,6-anhydro ring formed by glucose is generated at the end of reaction [10]. Since flame retardant finishing of cotton fabrics and garments becomes necessary to improve human safety, most of the researchers in the area of textile flame retardant finishing have focused on reducing the flammability of cotton [22].

Most of flame retardant treatments, formulations and additives have been developed since 1950-1980 but increasing concerns over the toxicological and environmental consequences of using such chemical species on textile substrates have created new chemistry and applications $[5,15,23]$. The flame retardant agent used for textile industry must be halogen-free, inexpensive, formaldehyde-free, stable and non-toxic. It should not decrease tensile, tear, burst strengths of cotton after treatment while withstanding hard water and hot alkaline launderings $[11,17]$. It is also very important not to make a difference in the outward appearance of the fabric; so it means not to change the hue of the dye and/or dyeability. It should not cause medical problems, such as any toxicity or skin irritation. Also there must not be any mutagenic or carcinogenic materials present in the flameretardant agent $[11,26]$.

Generally used effective fire retardants like N-methylol dimethyl phosphono propionamide (MDPA) commonly named as Pyrovatex and Tetrakishydroxymethylphosphonium chloride (THPC) are not known as environment friendly because Pyrovatex contains toxic formaldehyde, which is released during synthesis, application, storage and consumer use. Formaldehyde is a known toxic, skin and eye irritant. Moreover, Pyrovatex required formaldehyde based trimethylolmelamine for optimum results, which will significantly increase the amount of formaldehyde in the recipe. On the other hand, THPC is also an efficient flame retardant but it requires an ammonia chamber during application which makes it less desirable and the release of pungent and toxic ammonias also a serious problem [12].

There has been interest to develop FR cotton fabrics by using halogen-free phosphorus-based compounds which act as flame retarding agents in condensed phase by increasing the amount of carbonaceous residues or by increased char formation $[1,5,15,18]$. 


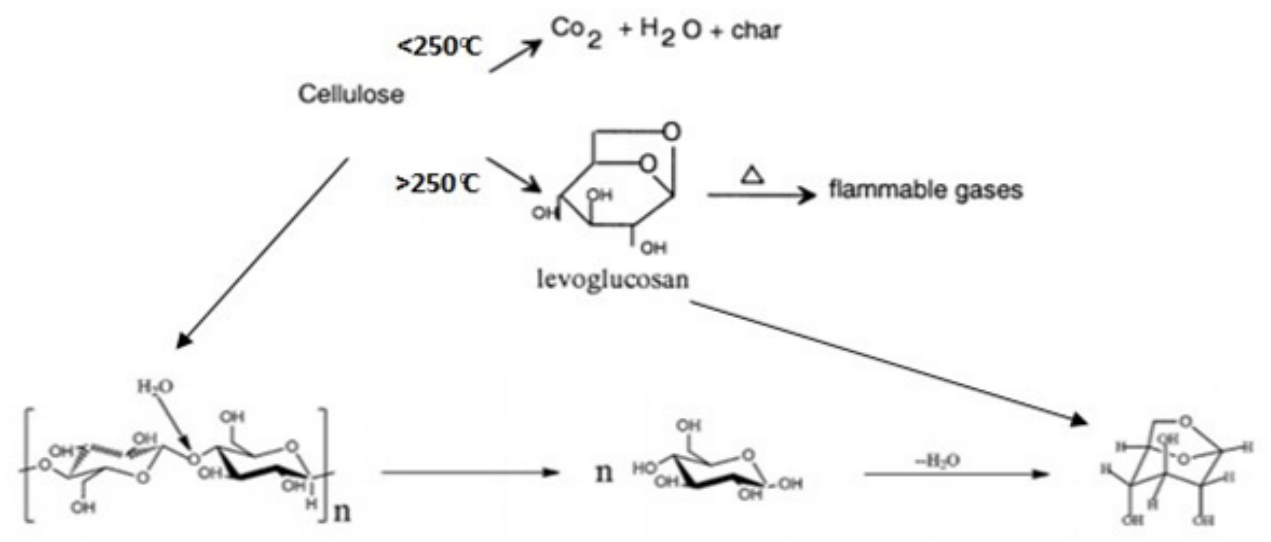

Fig. 1. Pyrolysis of cellulose $[3,25]$

For a long time, various forms of organophosphorus based flame retardants like phosphates, phosphoramide, phosphonate and phosphonium salts have been developed and used in flame retardant finishing of cellulosic fabrics. Current government regulations have raised safety and environmental protection standards on flame retardants, which has led to renewed interest on development of environmentally friendly structures $[5,16]$.

In this study, in order to compare the results with well-known and widely used commercial FRs, we used natural structured flame retardant agent that is water based, costeffective and liquid blend of a mineral formula of limestone which was actually developed in Balıkesir, Turkey in order to provide an alternative flame retardant of wood based materials such as cellulosic textile materials against burning. It was reported in its invention proofs and in the literature $[8,9,14,19]$ that it is significantly improves the fire-resistive characteristics of wood based materials and it shows insecticide and fungicide effects without any harmful adverse effect on humans, animals or environment. All three types of FR agents were applied on cotton fabric and performance tests beside characterization analysis of treated cotton fabrics were investigated in this study.

\section{EXPERIMENTAL}

\subsection{Material}

$100 \%$ plain weave cotton fabric with the yarn count of 28.8 $\mathrm{Ne}$ (35 warp/cm x 19 weft/cm, Berteks Company), Aguazm Ultra 1200 (amylase enzyme-Alfa Kimya), Imerol JW.TR liquid (fatty alkoxide- Clariant), Stabilizer SOF Liquid (stabilizer-Clariant) caustic soda and hydrogen peroxide (Sigma Aldrich), Remazol Brilliant Blue R (reactive dyestuffDystar), Firetex (colorless, odorless and a clear liquid which has a $\mathrm{pH}$ value of 8.2 and includes $\mathrm{CaCO}_{3}, \mathrm{Ba}, \mathrm{Ni}$ and $\mathrm{Mg}$ components that was produced by Kale Natural, Balıkesir, its properties was indicated in our previous study Ömeroğullari et al., 2011), Exaflam NAS (non-durable inorganic and organic salt mixture FR agent-MaiTürk), Apyrol BK (non-durable phosphate and nitrogen mixture FR agent, $\mathrm{CHT}$ ) were used in the study.

\subsection{Method}

In order to carry out the pre-treatment procedure of raw cotton fabric, first desizing process was performed with 0.3 $\mathrm{gr} / \mathrm{L}$ Aquazym Ultra $1200 \mathrm{~N}$ amylase enzyme at $75{ }^{\circ} \mathrm{C}$ with acetic acid. For bleaching procedure, $1 \mathrm{ml} / \mathrm{L}$ Imerol JW TR liquid, $0.5 \mathrm{ml} / \mathrm{L}$ Stabilizer SOF Liquid, $3 \mathrm{ml} / \mathrm{L} 36^{\circ}$ Bé caustic soda, $3 \mathrm{ml} / \mathrm{L}$ hydrogen peroxide (35\%) were applied on desized cotton fabric at $85{ }^{\circ} \mathrm{C}$ and warm and cold water washing procedure was followed. Dyeing procedure of cotton fabric was started with $2 \%$ reactive dyestuff, $40 \mathrm{~g} / \mathrm{L}$ salt and $2 \mathrm{~g} / \mathrm{L}$ wetting agent at $40{ }^{\circ} \mathrm{C}$ for $20 \mathrm{~min}$, then $20 \mathrm{~g} / \mathrm{L}$ caustic soda was added and samples were dyed in this bath for more $60 \mathrm{~min}$. All pre-treatment and dyeing processes were carried out in a beaker dyeing machine (Mathis Labomat BFA, Switzerland). Finally neutralization with acetic acid and washing procedure was performed on dyed cotton fabrics. After each finishing procedure (pre-scouring and dyeing) and also on untreated raw cotton fabric, in order to improve the flame retardant properties of samples, FR agents were applied with pad-dry process. $400 \mathrm{~g} / \mathrm{L}$ Exaflam NAS, $400 \mathrm{~g} / \mathrm{L}$ Apyrol BK, pure Firetex liquid and $400 \mathrm{~g} / \mathrm{L}$ Firetex were applied with $80 \%$ wpu (wet pick-up) on raw, pre-treated and dyed cotton fabrics in a vertical padder (Mathis VFM, Switzerland). FR treated cotton fabrics were dried at $120{ }^{\circ} \mathrm{C}$ for $3 \mathrm{~min}$ in drying oven (Nüve FN 500). All FR finish procedures were carried out according to their commercial prospectus. Here are the FR recipe and fabric codes used during the study which was performed in laboratory conditions:

1: Pure Firetex liquid 2: 400g/L Firetex 3: $400 \mathrm{~g} / \mathrm{L}$ Exaflam NAS 4: $400 \mathrm{~g} / \mathrm{L}$ Apyrol BK

R: Raw cotton fabric P: Pre-treated cotton fabric D: Dyed cotton fabric W: Multiple washing

\subsection{Washing Process}

In order to investigate the effect of multiple washings, the FR treated cotton fabrics were washed five times after the finishing process according to the AATCC M7 standard which is a laboratory practice for home laundering fabrics prior to flammability testing to differentiate between durable and non-durable finishes.

\subsection{Performance Tests}

\subsubsection{Measuring Weight}

In order to determine the moisture gained by fabrics in a month, right after each FR pad-dry process and 30 days later, weight of FR treated cotton fabrics were measured on 
precision scale, separately. For 30 days, all FR treated cotton fabrics were conditioned at $65 \%$ relative humidity and $20 \mathrm{C}$ laboratory conditions.

\subsubsection{Burning Test}

Burning test of FR treated and untreated all cotton fabrics were tested by vertical IMO A471 edge test method with 5 and $15 \mathrm{sec}$ flame exposure. 5 specimens were used for each sample. The char lengths were measured after the flame is distinguished and arithmetic means of measurements were calculated. In order to pass IMO A471 test successfully, char length shouldn't be over $150 \mathrm{~mm}$.

\subsubsection{Color Spectrums}

CIE $L^{*}, a^{*}, b^{*}, \Delta E$ values, whiteness and yellowness indexes of untreated and all FR treated cotton fabrics were measured by Konica Minolta CM 3600 D Spectrophotometer.

\subsection{Characterization Tests}

\subsubsection{SEM}

The surface morphology of untreated and treated cotton fabrics were scanned by a ZEISS/EVO 40 electron microscope at $10 \mathrm{kV}$ under a high vacuum at $\times 1500$ magnification after being coated with gold-palladium (Au-PI) at a thickness of 40-50 nm by a BAL-TEC SCD 005 coating device.

\subsubsection{FTIR-ATR}

FT-IR ATR spectra of the untreated and treated cotton fabrics were investigated by a Thermo Nicolet 6700 device in a wave number range of $525-4000 \mathrm{~cm}^{-1}$.

\section{RESULTS AND DISCUSSION}

\subsection{Weight Results}

In our previous study [14], it was realized that at the end of the pad-dry process, the polyester fabric treated with Firetex absorbed moisture and gave a sense of wetness after keeping them in laboratory conditions for half an hour. As it was determined on polyester before, there was a sense of wetness on the cotton fabric after Firetex treatment in this study too. So, it was decided to measure the weight right after the pad-dry process and also after conditioning samples for 30 days in laboratory environment in order to determine the moisture absorbed by the fabrics. Add-on values (\%) and increase in weight (\%) of FR treated cotton fabrics after 30 days were showed at Table 1, respectively. According to the results, after 30 days, the highest increase in weight was (14.3\%) belong to P1 cotton fabric which was only pre-treated and applied with pure Firetex. When Firetex was diluted with water and performed as $400 \mathrm{~g} / \mathrm{L}$ seen as recipe $2(R 2, P 2, D 2)$, there was a decrease in percentages which considered that diluting Firetex with water reduced the effect of its mechanism so that the increase in weight was not so high as pure Firetex treatment. However, it was also realized that all Firetex FR treatment provided moisture increase occurred on all treated cotton fabrics regardless of being raw, pre-treated or dyed. It could be because of its $\mathrm{CaCO}_{3}$ and mineral blend which may have an ability to absorb moisture. The increase in P1 was higher than dyed and raw cotton fabric because it was considered that wax and fatty structures existing on raw cotton fabric were removed by pre-scouring process so that hydrophilic structure of cotton fabric could absorb moisture easily on itself when compared to raw and dyed samples. On the other hand, when inorganic/organic salt based FR and phosphate structured FR treated fabrics were investigated, it could be clearly seen that there wasn't a significant increase in weight even after 30 days when compared to recipe 1 or recipe 2 which are Firetex treatments.

Table 1. Add-on values (\%) after pad-dry process and increase in weight $(\%)$ of FR treated cotton fabrics after 30 days

\begin{tabular}{|c|c|c|}
\hline $\begin{array}{c}\text { Samples of } \\
\text { treated cotton } \\
\text { fabrics }\end{array}$ & $\begin{array}{c}\text { Add-on values (\%) } \\
\text { after pad-dry } \\
\text { process }\end{array}$ & $\begin{array}{c}\text { Increase (\%) in } \\
\text { weight of FR } \\
\text { treated cotton } \\
\text { fabrics after 30 } \\
\text { days }\end{array}$ \\
\hline R1 & 6.8 & 7.3 \\
\hline P1 & 11.2 & 14.3 \\
\hline D1 & 10.6 & 12.8 \\
\hline R2 & 5.8 & 6.3 \\
\hline P2 & 10.9 & 13.8 \\
\hline D2 & 9.3 & 11.3 \\
\hline R3 & 3.9 & 4.0 \\
\hline P3 & 5.0 & 5.0 \\
\hline D3 & 4.4 & 4.4 \\
\hline R4 & 4.0 & 4.1 \\
\hline P4 & 4.4 & 4.4 \\
\hline D4 & 4.2 & 4.2 \\
\hline
\end{tabular}

The decrease in weight of FR treated cotton fabrics after 5 times washing process were clearly seen at Table 2 . In all recipes there was a decrease in weight of FR treated cotton fabrics after multiple washing which was suggested as all FR types used in this study could easily remove by water, detergent and mechanical movement. Significant decrease in weight (\%) was indicated when the pre-treated or dyed and FR applied cotton fabrics (P1-P4 and D1-D4) were washed 5 times. Since there was more penetration of FR agent into the fabric was occurred after pre-treatment of cotton fabrics because of improving hydrophilicity of cotton fabrics by removing fatty acid like particles on raw cotton fabrics and as all types of FR agents showed non-durability against multiple washing, the decreases in weight were more significant on pre-treated and dyed fabrics when compared to raw cotton fabrics (R1-R4).

Table 2.Decrease in weight (\%) of FR treated cotton fabrics after 5 cycle washing

\begin{tabular}{|c|c|c|c|c|c|}
\hline Samples & $\begin{array}{c}\text { Decrease (\%) in } \\
\text { weight after } \\
\text { washing }\end{array}$ & Samples & $\begin{array}{c}\text { Decrease(\%) in } \\
\text { weight after } \\
\text { washing }\end{array}$ & $\begin{array}{c}\text { Samples } \\
\text { Decrease (\%) in } \\
\text { weight after } \\
\text { washing }\end{array}$ \\
\hline R1 & 27.5 & P1 & 61.5 & D1 & 49.6 \\
\hline R2 & 12.7 & P2 & 26.5 & D2 & 25.5 \\
\hline R3 & 21.4 & P3 & 30.7 & D3 & 28.6 \\
\hline R4 & 16.7 & P4 & 29.7 & D4 & 27.0 \\
\hline
\end{tabular}




\subsection{Burning Test Results}

Burning test of FR treated and untreated all cotton fabrics were tested by IMO A471 edge test method with 5 and 15 sec flame exposure. The char lengths of them were showed at Table 3 below.

Untreated and 5 times washed-treated cotton fabrics were burned totally so it was considered that none of FR agents including Firetex used in this study showed durable effect against washing process. However, it was clearly indicated according to IMO A471 standard that the char lengths of pure Firetex treated cotton fabrics which determined as recipe 1 was very close the FR agents that have a commercial use in textile industry, referred as recipe 3 and 4 . Thus, it was concluded that Firetex improved the flame retardant effect on cotton fabric and it has a good flame retardant effect and it could be an alternative FR chemical effective on cotton fabrics likewise the other FR agents frequently used in textile industry. As its FR mechanism was effective on wood materials $[9,14,19]$ and it was considered that Firetex could improve the flame retardant effect of cellulosic based materials as an indicated result in Table 3. This result could attribute to the Firetex's main component, $\mathrm{CaCO}_{3}$ which provides a heat sink on the fibre and absorbs enough heat so that pyrolysis temperature of the cotton is not reached and no combustion takes place [17]. As Firetex water based liquid was a blend of a mineral formula of limestone which includes calcium carbonate, it was mentioned in the literature that some of mineral fillers decompose and absorb energy during combustion. As indicated in Tomak and Cavdar's study (2013) that calcium carbonate widely used mineral filler decomposes at temperatures between $700{ }^{\circ} \mathrm{C}$ and $900{ }^{\circ} \mathrm{C}$ and absorbs $1800 \mathrm{~kJ} / \mathrm{kg}$. It was also mentioned that the decomposition of carbonate minerals is endothermic and causes a decrease in flame temperature. Apart from cooling effect and quenching of the flames, fire retardancy of carbonate minerals is also enhanced by a kind of ceramic layer being formed on the surface of forest fuels that protects the ignitable materials from further attacks of flames and heat [19].

When compared to raw and dyed cotton fabrics, generally all pre-treated fabrics which were desized and bleached before FR treatment showed better FR effects on cotton. It was considered that wax and fatty structures existing on raw cotton fibers prevented the penetration of FR agents because of its hydrophobic characteristics while dyestuff and auxiliary chemicals in dye bath could affect FR mechanism in worse [13]. It was also determined due to the burning test results that diluting Firetex with water decreases the flame retardant effect, however the char lengths were still in the range between $2.6-4.7 \mathrm{~cm}$ which were in acceptable values after ignition.

\subsection{Color Spectrums}

According to color spectrum measurement, $\Delta \mathrm{E}$ values, yellowness and brightness indexes of raw, pre-treated and dyed fabrics after FR finishing were showed in Table 4, 5 and 6 , respectively. Color spectrum values of 5 times washed cotton fabrics after FR treatment were also indicated in each table as RW, PW and DW referring FR treated raw, pre-treated and dyed cotton fabrics after multiple washing, respectively.

As seen in Table 4, pure-Firetex treated raw cotton fabric showed the highest $\Delta \mathrm{E}$ value among the other recipes which was determined as Firetex's components caused color changes on raw cotton fabrics after treatment which was more significant than rest of the FR agents. When this $\Delta \mathrm{E}$ value was compared to $\mathrm{R} 2$, which Firetex was diluted with water before treatment, it was seen that color change was decreased. When yellowness and brightness indexes were investigated, it was clearly seen that all FR treatments caused increase in yellowness, however; pure Firetex treated raw cotton fabric had the highest yellowness index. After multiple washing processes, it was determined that brightness indexes of all treated fabrics were increased. This result was contributed to the fact that all recipes used in this study was indicated as non-durable treatment against washing which FR agents were removed easily with washing process; however it was also seen that brightness indexes were higher than untreated raw fabric which could be contributed to some of the waxy and fatty structures existing on raw cotton fabrics were also removed beside the FR agent by the washing and the detergent used in multiple washing process could had also a bleaching effect on raw materials.

Table 3. Char lengths of FR treated cotton fabrics

\begin{tabular}{|c|c|c|c|c|c|c|c|c|c|c|c|c|}
\hline \multirow{2}{*}{$\begin{array}{l}\text { Exposure time of flame } \\
\text { (sec) }\end{array}$} & \multicolumn{12}{|c|}{ Char Lengths of FR treated cotton fabrics (cm) } \\
\hline & R1 & P1 & D1 & $\mathbf{R 2}$ & P2 & D2 & R3 & P3 & D3 & R4 & P4 & D4 \\
\hline 5 & 3.1 & 2.1 & 2.6 & 3.6 & 2.6 & 3.0 & 3.2 & 2.3 & 2.8 & 3.1 & 2.2 & 2.8 \\
\hline 15 & 4.2 & 3.2 & 3.6 & 4.7 & 3.7 & 4.0 & 4.3 & 3.5 & 4.0 & 4.2 & 3.3 & 3.9 \\
\hline
\end{tabular}

Table 4. Color spectrums, brightness and yellowness indexes of treated and treated-washed raw cotton fabrics

\begin{tabular}{|c|c|c|c|c|c|c|}
\hline \multirow{2}{*}{$\begin{array}{l}\text { Samples of treated and } \\
\text { treated-washed raw } \\
\text { cotton fabrics }\end{array}$} & \multicolumn{3}{|c|}{ CIE LAB } & \multirow[b]{2}{*}{$\Delta \mathbf{E}$} & \multirow[b]{2}{*}{$\begin{array}{l}\text { Yellowness index } \\
\text { (ASTM D1925) }\end{array}$} & \multirow[b]{2}{*}{$\begin{array}{c}\text { Brightness index } \\
\text { (Stensby) }\end{array}$} \\
\hline & $L^{*}$ & $a^{*}$ & $\mathbf{b}^{*}$ & & & \\
\hline Raw cotton fabric & 84.560 & -1.205 & -11.625 & - & 25.519 & 53.902 \\
\hline $\mathrm{R} 1$ & 83.321 & -1.473 & -16.522 & 5.058 & 34.851 & 41.918 \\
\hline $\mathrm{R} 2$ & 89.018 & -2.018 & -13.727 & 2.731 & 30.436 & 49.638 \\
\hline R3 & 86.615 & -1.135 & -13.240 & 2.175 & 28.039 & 51.305 \\
\hline R4 & 85.703 & -1.605 & -13.257 & 2.815 & 28.542 & 52.316 \\
\hline RW1 & 87.972 & -0.806 & -8.207 & 4.846 & 18.049 & 65.024 \\
\hline RW2 & 88.249 & -0.630 & -7.106 & 5.862 & 15.711 & 67.685 \\
\hline RW3 & 88.240 & -0.683 & -8.124 & 5.108 & 17.728 & 65.11 \\
\hline RW4 & 87.873 & -0.780 & -7.795 & 5.082 & 17.245 & 65.901 \\
\hline
\end{tabular}


In Table 5, the $\Delta \mathrm{E}$ values, brightness and yellowness indexes of washed and unwashed pre-treated cotton fabrics after FR treatment were showed. As a bleaching process was carried out with hydrogen peroxide in pre-treatment of cotton fabrics, there was a significant increase in brightness index of pre-treated cotton fabric before FR treatment. However; this highest brightness value was decreased by FR treatments which have inorganic-organic salt mixture or phosphorus based components that cause yellowness on cotton material. Likewise previous table result, most change in $\Delta \mathrm{E}$ values was showed in $\mathrm{P} 1$ fabric which was treated with pure-Firetex. After 5 times washing, brightness indexes of FR treated cotton fabrics were increased while the yellowness indexes were at the lowest range. In Table 6, like the other results mentioned in color spectrums part, it was seen that pure Firetex caused most significant color changes on dyed cotton fabrics when compared to the other FR agents. This result was associated to the dense mixture of mineral and calcium carbonate as components existing in Firetex chemical structure. It was also determined that diluting Firetex with water decreased the color change occurred on dyed cotton fabrics.

\subsection{Scanning Electron Microscope Images}

In Figure 2, SEM micrographs of untreated and FR treated cotton fabrics which were pre-treated at the beginning of the study were showed. According the SEM images, it was clearly seen that cotton surface was smooth at Fig 2a which cotton fabric had no FR treatment while some chemical particles were seen at Fig. $2 b, 2 c$ and $2 d$ due to the components included by FR agents. However, chemical particles of Firetex were seen denser than other FR agents in SEM images. This result was attributed to the minerals existing in Firetex such as sodium, potassium and magnesium besides calcium carbonate particles which have the highest content with the value of $100 \mathrm{~g} / \mathrm{L}$ according to the ICP-OES results indicated by Kale-Natural.

\subsection{FTIR-ATR analysis}

FT-IR (ATR) spectrums of untreated and all FR treated cotton fabrics were shown in Figure 3.For all samples a broad band between 3100 and $3700 \mathrm{~cm}^{-1}$ centered around $3360 \mathrm{~cm}^{-1}$ illustrated characteristics of $\mathrm{OH}$ functional groups in cellulose. A strong adsorption peak at $1030 \mathrm{~cm}^{-1}$ is a result of the overlapping bands attributed to functional groups of cellulose, namely the $\mathrm{C}-\mathrm{C}, \mathrm{C}-\mathrm{O}$ and $\mathrm{C}-\mathrm{O}-\mathrm{C}$ stretching vibrations [20]. The sharp peak of Firetex treated fabric can be clearly in the figure around $3324 \mathrm{~cm}^{-1} \mathrm{O}-\mathrm{H}$ stretching region which could be attributed to the water adsorption arising from calcium carbonate chemical structure [2]. The sharp peak around $1616 \mathrm{~cm}^{-1}$ is assigned to stretching of the $\mathrm{C}=\mathrm{N}$ bond [7] which could be exist in Firetex and also in Apyrol BK that includes nitrogen components in its structure.

Table 5. Color spectrums, brightness and yellowness indexes of treated and treated-washed pre-treated cotton fabrics

\begin{tabular}{|c|c|c|c|c|c|c|}
\hline \multirow{2}{*}{$\begin{array}{l}\text { Samples of treated and } \\
\text { treated-washed pre- } \\
\text { finished cotton fabrics }\end{array}$} & \multicolumn{3}{|c|}{ CIE LAB } & \multirow[b]{2}{*}{$\Delta \mathbf{E}$} & \multirow[b]{2}{*}{$\begin{array}{l}\text { Yellowness index } \\
\text { (ASTM D1925) }\end{array}$} & \multirow[b]{2}{*}{$\begin{array}{c}\text { Brightness index } \\
\text { (Stensby) }\end{array}$} \\
\hline & $L^{*}$ & $a^{*}$ & $\mathbf{b}^{*}$ & & & \\
\hline $\begin{array}{l}\text { Pre-treated cotton fabric } \\
\text { before FR treatment }\end{array}$ & 93.202 & -0.327 & -1.750 & - & 4.657 & 85.377 \\
\hline $\mathrm{P} 1$ & 92.490 & -0.454 & -3.641 & 2.025 & 8.174 & 78.792 \\
\hline $\mathrm{P} 2$ & 91.982 & -0.288 & -2.894 & 1.673 & 6.917 & 80.770 \\
\hline P3 & 91.617 & -0.381 & -2.601 & 1.8 & 6.298 & 80.879 \\
\hline $\mathrm{P} 4$ & 92.749 & -0.477 & -3.306 & 1.625 & 7.531 & 80.061 \\
\hline PW1 & 92.725 & -0.046 & -0.779 & 2.6 & 0.363 & 93.227 \\
\hline PW2 & 92.957 & -0.087 & -0.490 & 2.266 & 0.090 & 92.276 \\
\hline PW3 & 92.963 & -0.018 & -0.886 & 2.665 & 0.634 & 93.649 \\
\hline PW4 & 93.082 & -0.055 & -0.701 & 2.469 & 0.291 & 93.144 \\
\hline
\end{tabular}

Table 6. Color spectrums, brightness and yellowness indexes of treated and treated-washed dyed cotton fabrics

\begin{tabular}{|c|c|c|c|c|c|c|}
\hline \multirow{2}{*}{$\begin{array}{l}\text { Samples of treated and } \\
\text { treated-washed dyed } \\
\text { cotton fabrics }\end{array}$} & \multicolumn{3}{|c|}{ CIE LAB } & \multirow[b]{2}{*}{$\Delta \mathrm{E}$} & \multirow[b]{2}{*}{$\begin{array}{l}\text { Yellowness index } \\
\text { (ASTM D1925) }\end{array}$} & \multirow[b]{2}{*}{$\begin{array}{c}\text { Brightness index } \\
\text { (Stensby) }\end{array}$} \\
\hline & $\mathrm{L}^{*}$ & $a^{*}$ & $\mathbf{b}^{*}$ & & & \\
\hline Dyed cotton fabric & 70.896 & 5.358 & 11.287 & - & \begin{tabular}{|l|}
32.511 \\
\end{tabular} & 52.320 \\
\hline $\mathrm{D} 1$ & 73.370 & 7.552 & 14.401 & 4.542 & 40.04 & 54.130 \\
\hline $\mathrm{D} 2$ & 72.324 & 5.428 & 12.035 & 1.614 & 33.628 & 52.300 \\
\hline D3 & 68.841 & 5.226 & 12.068 & 2.202 & 34.751 & 48.180 \\
\hline D4 & 72.317 & 4.048 & 10.66 & 2.03 & 29.474 & 51.456 \\
\hline DW1 & 73.512 & 6.998 & 11.648 & 3.109 & 33.827 & 58.798 \\
\hline DW2 & 72.041 & 5.009 & 9.832 & 1.884 & 28.582 & 55.819 \\
\hline DW3 & 72.640 & 4.860 & 9.191 & 2.772 & 26.942 & 57.516 \\
\hline DW4 & 72.153 & 5.127 & 9.707 & 2.032 & 28.428 & 56.552 \\
\hline
\end{tabular}




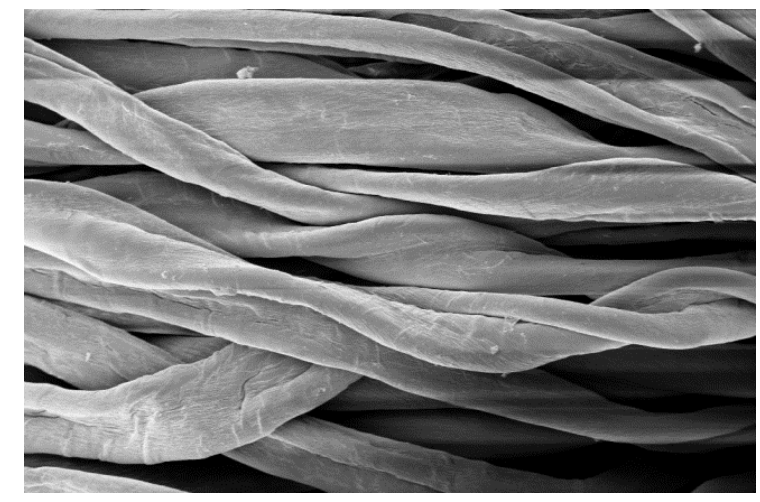

a) Untreated cotton fabric

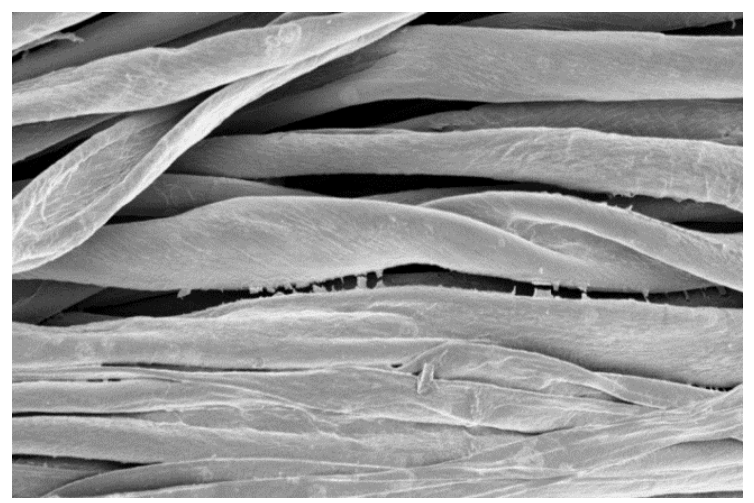

c) Exaflam NAS treated cotton fabric

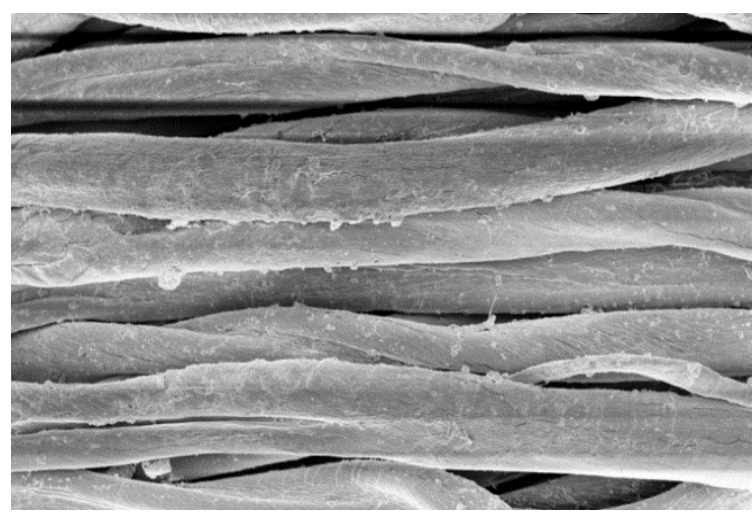

b) Pure Firetex treated cotton fabric

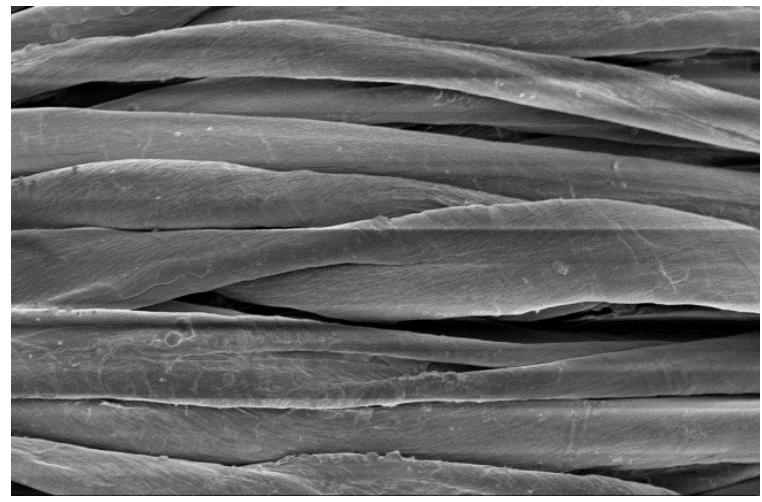

d) Apyrol BK treated cotton fabric

Fig 2. SEM micrographs of untreated and FR treated cotton fabrics

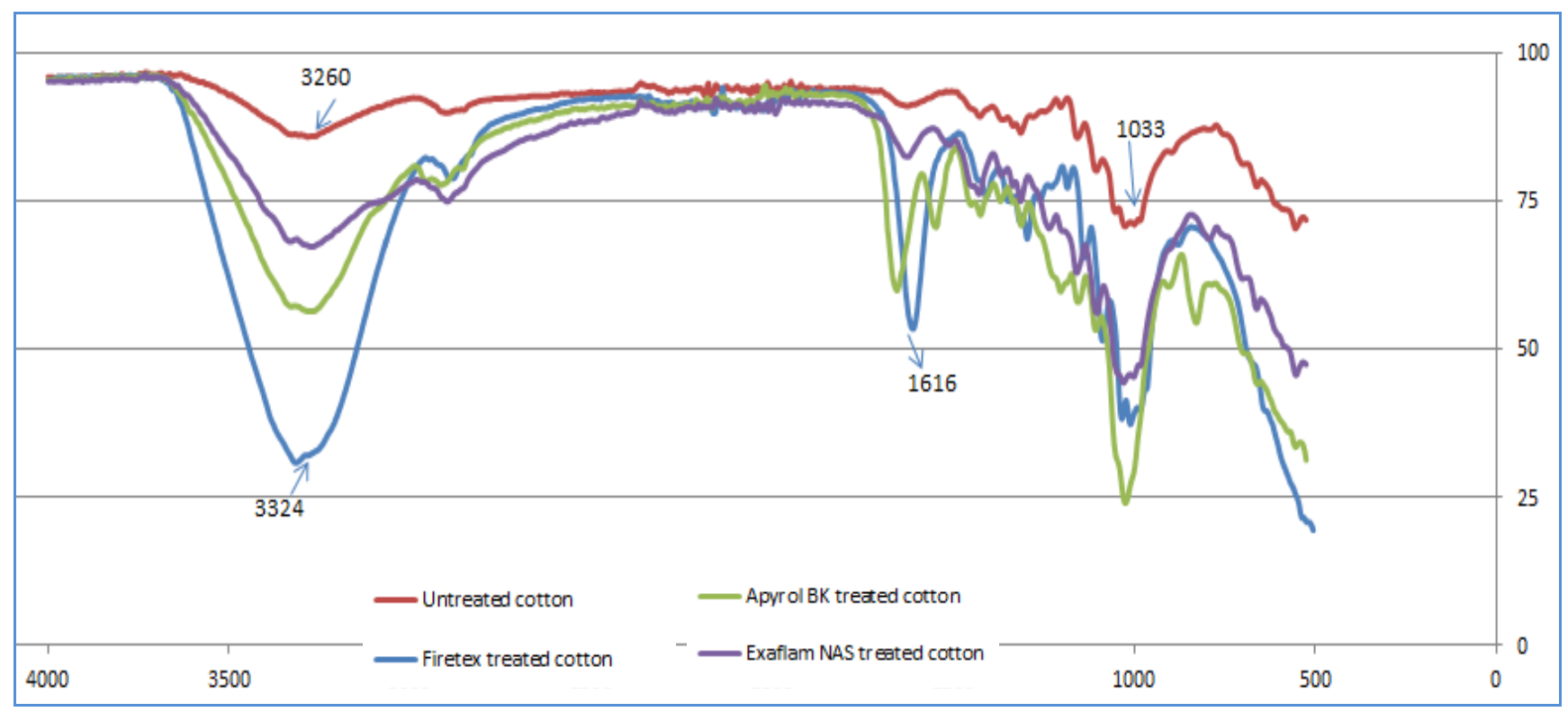

Fig. 3. FTIR-ATR analysis of untreated and FR treated cotton fabrics

\section{CONCLUSION}

Since Firetex was produced as a fire-extinguisher especially in forest fires to protect wood based materials which have the cellulosic structure at the base, the flame retardancy effect of this material on $100 \%$ cotton fabric which has the same chemical structure based on cellulose was investigated in this study. As a conclusion, it was determined according to the burning test results that Firetex could be used as an effective FR agent on cotton fabrics due to the improved the flame retardant effect on cotton fabrics which was efficient as much as other FR agents used widely in textile industry. It was indicated in this study that after Firetex treatment especially when it is not diluted with water, a sense of wetness was realized on treated cotton fabrics likewise in our previous study about Firetex. Hence, in order to determine the moisture absorption on the 
samples, weights of all untreated and treated cotton fabrics were measured after pad-dry system, after 30 days conditioning in lab. and after washing process, respectively. After 30 days, the measurement showed that especially pure Firetex caused a significant increase in weight by absorbing moisture in air around $14 \%$ which was the highest value among all samples. According to the burning test results, Firetex treatment were compared to conventional FR agents widely used in textile industry and determined that it improved flame retardant effect of cotton fabrics as much as the other FR agent which considered as Firetex could be an alternative FR agent using on cotton fabrics in order to provide an environmental-friendly, costeffective, natural structured flame retardant treatment which does not contain toxic effect, formaldehyde or halogen in its chemical structure. However, it was determined that Firetex caused color changes on cotton fabrics after treatment. None of the three types of FR agents showed durable effect against multiple washing. For further studies about Firetex's effect on textiles, in order to prevent the moisture absorption of Firetex treated material and also to provide a durable flame retardant application, a detailed research can be carried out.

\section{REFERENCES}

1. Abdel Mohdy, F. A.,2003,"Graft Copolymerization of Nitrogen And Phosphorus Containing Monomers onto Cellulosics for Flame Retardant Finishing of Cotton Textiles". Journal of Applied Polymer Science, 89(9), pp: 2573-2578.

2. Al-Hosney, H. A., \&Grassian, V. H. ,2005, "Water, Sulfur Dioxide and Nitric Acid Adsorption on Calcium Carbonate: A Transmission and ATR-FTIR Study”. Physical Chemistry Chemical Physics, 7(6), pp:1266-1276.

3. Alongi, J., Ciobanu, M., \&Malucelli, G.,2012,“Thermal Stability, Flame Retardancy And Mechanical Properties of Cotton Fabrics Treated with Inorganic Coatings Synthesized Through Sol-Gel Processes". Carbohydrate Polymers, 87(3), pp: 2093-2099.

4. Cheng, X., \& Yang, C. Q. 2009, "Flame Retardant Finishing of Cotton Fleece Fabric: Part V. Phosphorus containing Maleic Acid Oligomers”. Fire and Materials, 33(8), pp: 365-375.

5. Gaan, S., \& Sun, G.,2007,"Effect Of Phosphorus Flame Retardants On Thermo-Oxidative Decomposition of Cotton”. Polymer Degradation and Stability, 92(6), pp: 968-974.

6. Horrocks, A. R., Kandola, B. K., Davies, P. J., Zhang, S., \& Padbury, S. A., 2005, “Developments in Flame Retardant Textiles-A Review”. Polymer Degradation and Stability, 88(1), pp: 3-12.

7. Karabudak, E., Kas, R., Ogieglo, W., Rafieian, D., Schlautmann, S., Lammertink, R. G.\&Mul, G.,2012,“Disposable Attenuated Total Reflection-Infrared Crystals From Silicon Wafer: A Versatile Approach To Surface Infrared Spectroscopy”. Analytical Chemistry, 85(1), pp: 33-38.

8. Kesik, H. I., Aydoğan, H., Çağatay, K., Özkan, O. E., \&Maraz, E. "Fire Properties of Scots Pine Impregnated with Firetex".

9. Kurt, C. Ö. Ş., Esen, R., \&Korkmaz, M., 2016, “The Determinated Combustion Properties of Fir Wood Impregnated With Fire-Retardants”. The Online Journal of Science and Technology-July, 6(3).

10. Lecoeur, E., Vroman, I., Bourbigot, S., Lam, T. M., \&Delobel, R.,2001,“Flame Retardant Formulations For Cotton”. Polymer Degradation and Stability, 74(3), pp: 487-492.

11. Lewin, M. ,2005, “Unsolved Problems and Unanswered Questions in Flame Retardanceof Polymers”. Polymer Degradation and Stability, 88(1), pp: 13-19.

12. Mohsin, M., Quatab, H. G., Sarwar, N., Ramzan, N., \& Ahmad, S. W. ,2017, “Synthesis of Halogen and Formaldehyde Free Bio Based Fire Retardant For Cotton". IndustriaTextila, 68(3), pp: 221.

13. Ozcan, G., Dayioglu, H., \&Candan, C. ,2004, "Impact of Finishing Processes on Flame Resistance of Knitted Fabric”. Textile Research Journal, 74(6), pp: 490-496.

14. Ömeroğullari, Z., \&Kut, D.,2011,"Investigation of Burning Behavior of Polyester Fabric with Using Natural Structured Flame Retardant Agent”. Journal of Textile \& Apparel/TekstilveKonfeksiyon, 21(4). v.4, pp: 364-368.

15. Reddy, P. R. S., Agathian, G., \& Kumar, A.,2005,“lonizing Radiation Graft Polymerized and Modified Flame Retardant Cotton Fabric”. Radiation Physics and Chemistry, 72(4), pp: 511-516.

16. Salmeia, K. A., Jovic, M., Ragaisiene, A., Rukuiziene, Z., Milasius, R., Mikucioniene, D., \&Gaan, S.,2016,"Flammability of Cellulose-Based Fibers and the Effect of Structure of Phosphorus Compounds on Their Flame Retardancy". Polymers, 8(8), pp: 293.

17. Schindler, W. D., \& Hauser, P. J. ,2004,“Chemical Finishing of Textiles”. Elsevier.

18. Tsafack, M. J., \&Levalois-Grützmacher, J., 2006, "Flame Retardancyof Cotton Textiles By Plasma-Induced Graft-Polymerization (PIGP)". Surface and Coatings Technology, 201(6), pp: 2599-2610.

19. Tomak, E. D., \&Cavdar, A. D. ,2013,“Limited Oxygen Index Levels of Impregnated Scots Pine Wood”. ThermochimicaActa, 573, pp: 181-185.

20. Ugur, Ş. S., Sariişik, M., \&Aktaş, A. H. ,2010, “The Fabrication of Nanocomposite Thin Films With TIO2 Nanoparticles By The Layer-By-Layer Deposition Method For Multifunctional Cotton Fabrics". Nanotechnology, 21(32), pp:325-603.

21. Weil, E. D., \&Levchik, S. V. ,2008, “Flame Retardants In Commercial Use or Development For Textiles”. Journal of Fire Sciences, 26 (3), pp: 243-281.

22. Wu, W., \& Yang, C. Q. 2006,"Comparison of Different Reactive Organophosphorus Flame Retardant Agents for Cotton: Part I. The Bonding of the Flame Retardant Agents to Cotton". Polymer Degradation and Stability, 91(11), pp: 2541-2548.

23. Yang, C. Q., \& Wu, W.,2003, "Combination of a Hydroxy Functional Organophosphorus Oligomer and A Multifunctional Carboxylic Acid As A Flame Retardant Finishing System For Cotton: Part II. Formation of Calcium Salt DuringLaundering”. Fire and Materials, $27(5)$, pp: $239-251$.

24. Yang, C. Q., \&Qiu, X., 2007, "Flame Retardant Finishing of Cotton Fleece Fabric: Part I. The Use Of A Hydroxy Functional Organophosphorus Oligomer and Dimethyloldihydroxylethyleneurea". Fire and materials, 31(1), pp: 67-81.

25. Zhang, X., Yang, W., \& Dong, C., 2013,“Levoglucosan Formation Mechanisms During Cellulose Pyrolysis”. Journal of Analytical and Applied Pyrolysis, 104, pp: 19-27.

26. Özdoğan, E., Korkmaz, A., \&Seventekin, N., 2007,“Eko-Teksve AB çevre Etiketi”.Tekstil ve Konfeksiyon Dergisi 3(1), pp:148-152. 